\section{Editorial: On IRIE Vol. 9}

Religion - from an evolutionary point of view - can be called the very first information business of humankind. The medicine man, the priest, the witch doctor were indeed the first institutions to deal with information only. Their core business was to provide information on the transcendent that is not directly present and accessible: the will of the goddess, the sense of life, what may come after death ... .

Information that is well sought after - today like in the early days. So over time many answers have been given on these and other religious topics all over the world. Formally spoken a huge amount of information has been produced in the various religions.

As substantial scientific progress has been achieved in the field of information science over the last decades, it is about high time to also reflect the relationship between information (respective the technology used to produce, store and distribute it) and an incumbent subject like religion. Yet the importance of that relationship cannot be overestimated as only a few examples may suggest:

- How many art treasures e.g. have been fallen victim to iconoclasms all over the world within as well as in-between various religions because of the disagreement if pictorial information is suitable for the divine.

- Besides the authority of the Pope the availability of the Bible to the people was in midst of the reformatory discourse and finally translated into the local language the Holy Book of Christianity was made accessible for the first time directly to nonacademic believers.

- Finally, most interestingly the technological revolution of Gutenberg's invention of printing with movable types coincided with the intellectual shift included with that reformatory transformation.

Against the backdrop that until today some religions rely heavily on oral traditions while others are (not only virtually) written in stone our question is not only if that makes any difference for the doctrine itself: the content to be developed and/or passed on. We particularly want to take the ethical point of view and ask the question of the morality involved in the different usage of information in the different religions. Will the technological revolution of the internet account for another religious one? Is it true that you can tell from one's media usage one's religious attitudes? And will the convergence within ICTs push a religious convergence adding another yet important facet to the notion of the global village to be promoted by the internet. And finally, is that ethically desirable?

We asked these questions and the editors of this issue: Udeani, Capurro and Frühbauer with notable support of Hausmanninger put them into a wonderful call for paper as well as into the introduction to this issue systemizing the problems involved in the relationship between 'Religion and IT'.

With Tamura \& Tamura, Cohen, Shields, Zeilinger, Siwaswaroop, Kenway and Stückelberger it found an impressive echo from all over the world ranging

- from fundamental, philosophical deliberations on the influence of media usage on religious characteristics

- over specific examples to be found in Japanese Religion, Hinduism, Judaism and Christianity

- to speculations on possible future developments of religion promoted by the current enhancements of ICTs.

Admitting that we are not able to present final answers here is especially in the field of religion no weakness at all. Thus, we confine ourselves with the hope to contribute substantially to the ongoing discourse on the subject and to your personal deliberations.

Yours sincerely,

the Editors 